\title{
THE EFFECTS OF AN INNOVATIVE TECHNOLOGY APPLIED AS VIRTUAL REHABILITATION ON CLINICAL OUTCOMES IN ANTERIOR CRUCIATE LIGAMENT INJURY
}

\author{
Onur Aydoğdu, ${ }^{1}$ Zübeyir Sarı, ${ }^{2}$ Ufuk Saadet Yurdalan, ${ }^{3}$ Gülden Mine Polat ${ }^{4}$
}

\begin{abstract}
In recent years, many different technologies on virtual rehabilitation have been produced and used in research. However, existing studies are limited because most of them focus on the balancing ability of the elderly or studied stroke patients with same systems. Thus, it is necessary to investigate the effects of a new virtual rehabilitation system in patients with Anterior Cruciate Ligament (ACL) Reconstruction. The purpose of this study was to investigate the effects of a virtual rehabilitation system using a MarVAJED ${ }^{\circledR}$ system which provides visual and auditory stimulus aimed at educating and controlling the joint proprioception, range of motion, pain intensity, and knee swelling in individuals with an ACL injury. A total of fifteen patients with ACL reconstruction participated in this study. In addition to conventional physiotherapy, a virtual rehabilitation treatment was applied with visual and auditory stimulus for a total of eight weeks, three sessions per week. There were statistically significant improvements in measures of proprioception, range of motion, pain intensity, and knee swelling between pre- and post - treatment $(\mathrm{p}<0.05)$. We concluded that this new VR system known as MarVAJED effectively treat ACL patients by improving proprioception, range of motion, and by decreasing pain intensity, and knee swelling.
\end{abstract}

UDC Classification: 617.3 ; DOI: http://dx.doi.org/10.12955/cbup.v5.1047

Keywords: Innovative Technology, Rehabilitation, Physiotherapy

\section{Introduction}

Knee joint injuries are common in activities of daily life as well as in sports activities. Anterior cruciate ligament (ACL) injuries are one of the most common knee injuries (Lange et al., 2015; Tichonova et al., 2016). ACL injuries do not recover spontaneously because of poor vascularization of the injured ligament. Therefore, when individuals injure their ACL, they should often take comprehensive rehabilitation (Takata et al., 2017).

Various treatment protocols after cruciate ligament injuries for rehabilitation have been studied, which focus on open versus closed chain exercises, early versus delayed weight bearing status, use of brace post operatively, accelerated versus non-accelerated rehabilitation, supervised versus home-based rehabilitation along with strength training, balance training, and criteria for return to play (Priyanka et al, 2017). Due to new trends, to accelerate recovery, innovative technology should be made an integral part of ACL rehabilitation.

Improvements in technology have made virtual rehabilitation popular and available in various rehabilitation systems. Virtual rehabilitation systems play an increasing role in rehabilitation. They provide an interactive environment and increased motivation for patients during the session (Ferreira et al., 2016). Virtual rehabilitation may be an appropriate device because it allows the clinician visual and auditory feedback to train their patients. In addition, it is possible with virtual rehabilitation to manipulate the environment that would be impractical or impossible to create in the real world (Gokeler et al., 2016).

In recent years, many different technologies on virtual rehabilitation have been produced and used in research however, existing studies are limited because most of them focus on the balancing ability of the elderly or studied in stroke patients with same systems (Park et al., 2015). Thus, it is necessary to investigate the effects of a new virtual rehabilitation system in patients with Anterior Cruciate Ligament (ACL) Reconstruction.

The purpose of this study was to investigate the effects of a virtual rehabilitation system using the MarVAJED ${ }^{\circledR}$ system which provides visual and auditory stimulus aimed for educating and controlling the joint on proprioception, range of motion, pain intensity, and knee swelling in individuals with ACL injury.

\footnotetext{
${ }^{1}$ Marmara University, Faculty of Health Sciences, Istanbul, Turkey, fztonuraydogdu @ hotmail.com

${ }^{2}$ Marmara University, Faculty of Health Sciences, Istanbul, Turkey, fztzubeyir@yahoo.com

${ }^{3}$ Marmara University, Faculty of Health Sciences, Istanbul, Turkey, ufukyurdalan @ hotmail.com

${ }^{4}$ Marmara University, Faculty of Health Sciences, Istanbul, Turkey, guldenpolat2002@yahoo.com
} 


\section{Methods}

A total of fifteen patients with ACL reconstruction participated in this study. In addition to conventional physiotherapy, a virtual rehabilitation treatment was applied with visual and auditory stimulus for a total of eight weeks, three sessions per week.

Visual and auditory stimuli were applied via the MarVAJED® system which was developed by Marmara University, Department of Physiotherapy and Rehabilitation with the aim of educating and controlling the joint as a virtual rehabilitation system.

Before and after intervention, proprioception was measured with a Biodex System Pro 4 Isokinetic Dynamometer (Sadeghi et al., 2017), the range of motion was measured with a universal goniometer, pain intensity was measured with a Visual Analogue Score (Huskisson, 1983), and knee swelling was measured with a tape measure (Jakobsen et al., 2010).

The study was planned as a clinical study and ethical approval was obtained from the Marmara University Faculty of Medicine Clinic Researches Ethical Board.

\section{MarVAJED}

MarVAJED is an innovative device that allows continuous evaluation of the deviation angle of 0.10 . The device allows evaluating different measurements such as: goniometric and proprioceptive assessment and changes of range of motion during physical activities. It also has a virtual rehabilitation application with visual and auditory stimulus. MarVAJED operates under both a direct and a smart phone system. The device includes the following components:

(1) Software and Smart Phone Panel - The android software had been specifically and exclusively designed for the purpose of the device and measurement control. The main role of the software is to control the values and direction of knee deviation, record and archive the patients' data, together with the results of repeated measurements (Figure 1).

(2) Device - The device consists of two parts: an upper and a lower which connect to each other and a smart phone via Bluetooth (Figure 2). It is possible to assess all directions of movement in almost all joints: flexion - extension, abduction - adduction, and internal - external rotation in the joint of shoulder, elbow, wrist, hip, knee, and ankle. In addition, patient data are stored in a database in the smart phone. Following the measurement, it can be easily exported to the PC with a desired format such as excel, pdf, etc.

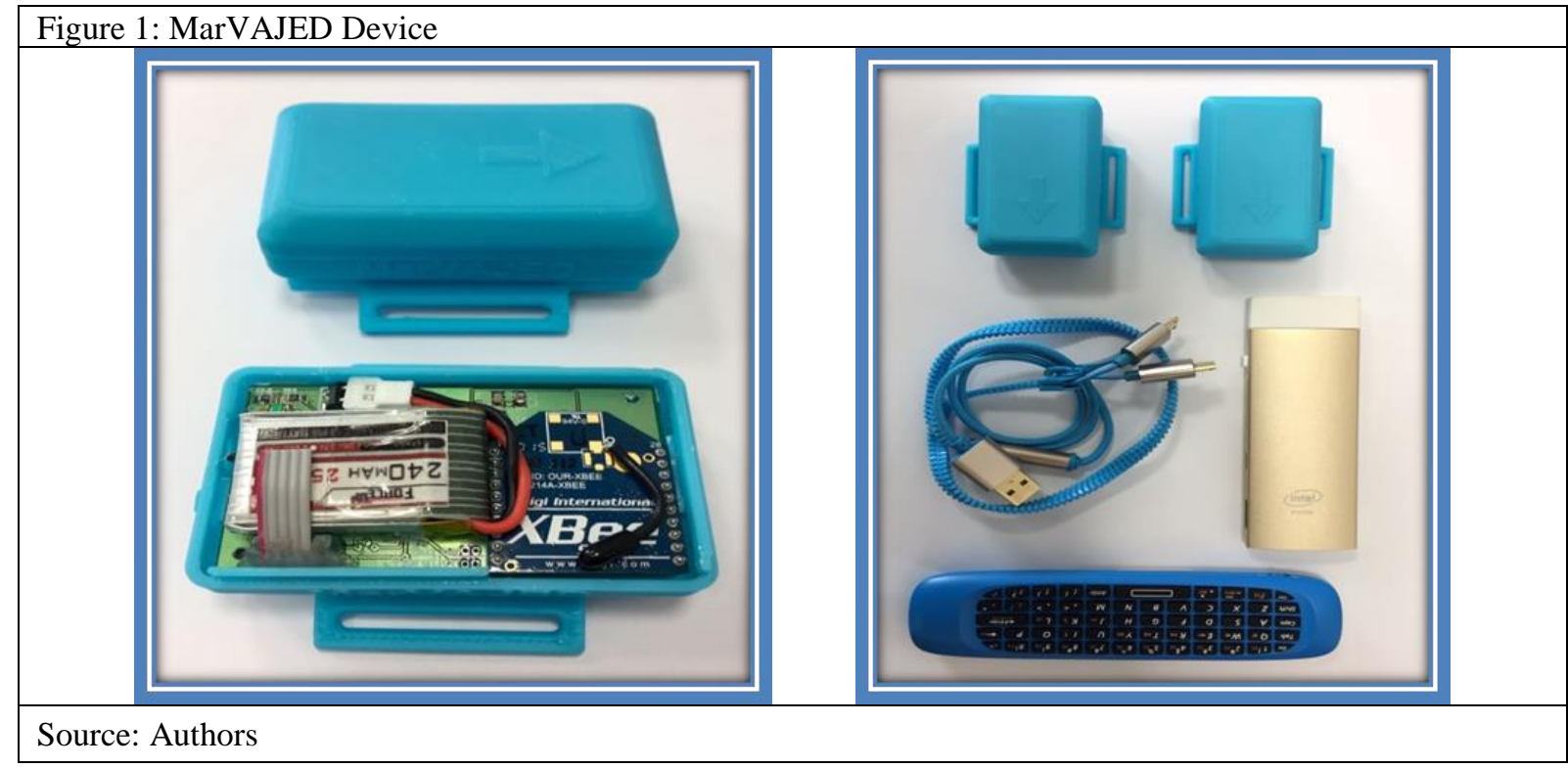

\section{Statistical Analysis}

All statistical analyses were performed using the software IBM SPSS Statistics version 11.5 (IBM Corporation, USA), with a $\mathrm{P}$ value $<0.05$ considered statistically significant. All numerical data were expressed as mean \pm standard deviation. Data obtained from patients before and after treatment were assessed by using the Wilcoxon Signed Test. 

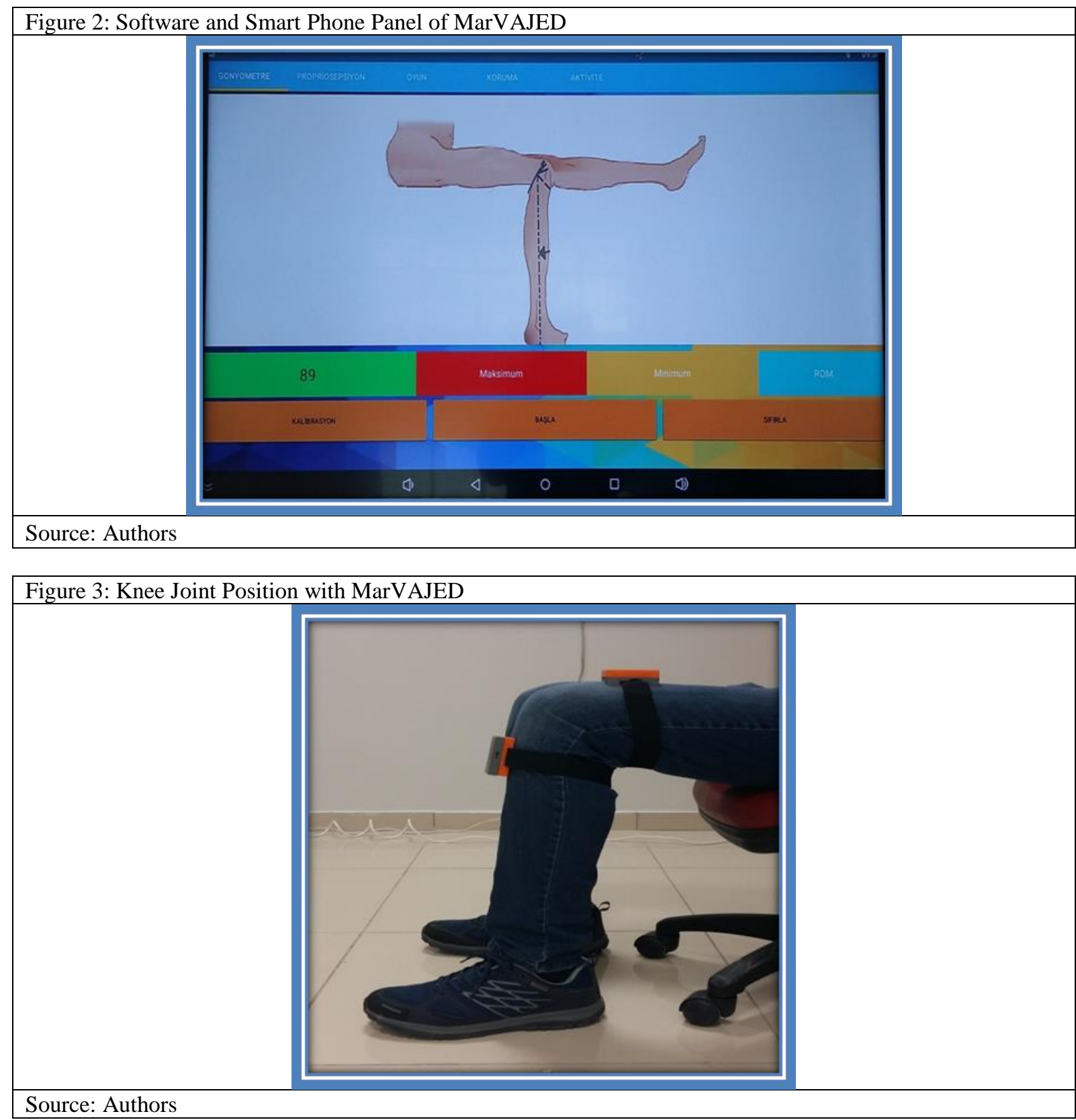

\section{Results}

The study included 2 females (13\%) and 13 males (87\%). A total of 15 patients completed the study (Table 1), SD: Standard deviation. There were statistically significant improvements in measures of proprioception, range of motion, pain intensity, and knee swelling between pre- and post-treatment $(p<0.05)$ (Table 2), $p_{1}$ : Comparison of intragroup post-treatment values with pre-treatment values. We encountered no adverse effects of our device in our trial.

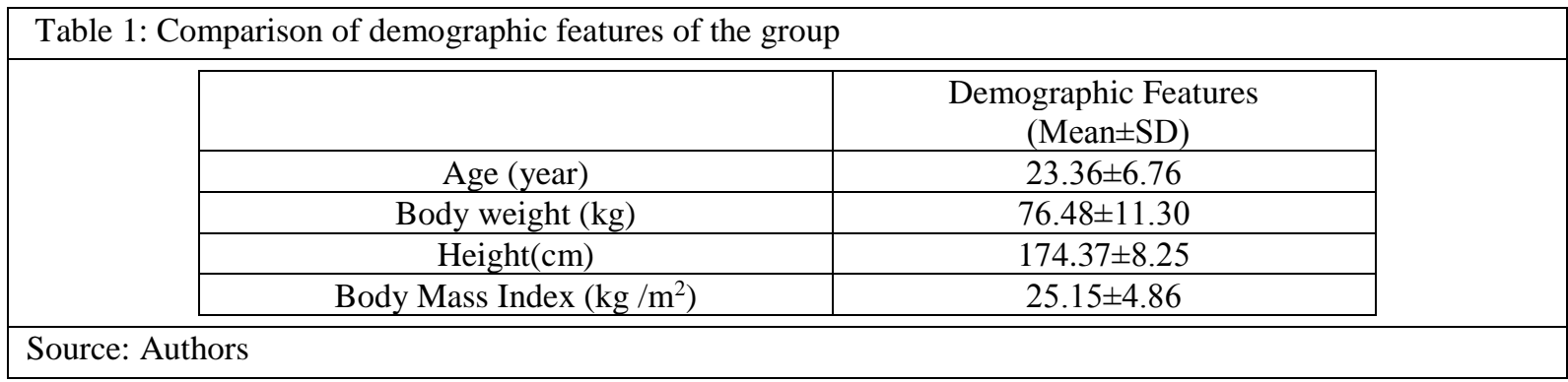




\begin{tabular}{|c|c|c|c|}
\hline & \multicolumn{3}{|c|}{ TREATMENT GROUP } \\
\hline & $\begin{array}{l}\text { Pre-Treatment } \\
(\text { Mean } \pm \text { SD })\end{array}$ & $\begin{array}{l}\text { Post-Treatment } \\
\text { (Mean } \pm \text { SD) }\end{array}$ & $\mathrm{p}_{1}$ \\
\hline Knee Proprioception (Degree) & $6.64 \pm 2.48$ & $3.29 \pm 1.75$ & 0.001* \\
\hline $\begin{array}{l}\text { Range of Motion } \\
\text { (Flexion Degree) }\end{array}$ & $118 \pm 7.94$ & $130.02 \pm 3.66$ & 0.001* \\
\hline Pain Intensity $(\mathrm{cm})$ & $4.53 \pm 1.79$ & $2.56 \pm 0.39$ & 0.001* \\
\hline Knee Swelling $(\mathrm{cm})$ & $2.63 \pm 1.51$ & $0.93 \pm 0.24$ & 0.001* \\
\hline
\end{tabular}

\section{Discussion}

The study investigated whether our innovative device - MarVAJED, providing a virtual rehabilitation system with visual and auditory stimulus aimed for educating and controlling the joint has beneficial effects on proprioception, range of motion, pain intensity, and knee swelling in individuals with an ACL injury. To our knowledge, this is one of the first clinical trials to determine the effects of virtual rehabilitation on patient outcomes in patients with an ACL injury.

The results of our study showed that the MarVAJED innovative device system used as a virtual rehabilitation decreased the pain intensity, and knee swelling in patients with ACL reconstruction. This clinical trial confirmed the hypothesized advantage of virtual rehabilitation in patients with ACL reconstruction.

\section{Conclusion}

We concluded that this new VR system known as MarVAJED effectively treated ACL patients by improving proprioception, range of motion, and by decreasing pain intensity, and knee swelling. Integration of technology into rehabilitation programmes may enhance assessment and rehabilitation. New technology systems may be more effective in increasing quality of life of patients.

\section{Acknowledgement}

This study was supported by Marmara University, Scientific Research Projects Committee (Project Number: SAG-C-DRP-200716-0374) and TÜBİTAK, The Scientific and Technological Research Council of Turkey (Project Number: 115E351).

\section{References}

Ferreira Dos Santos L, Christ O, Mate K (2016). Movement visualisation in virtual reality rehabilitation of the lower limb: a systematic review. Biomed Eng Online, 15(Suppl 3):144.

Gokeler, A, Bisschop M, Myer GD, Benjaminse A, Dijkstra PU, Keeken H, Raay J, Burgerhof J, Otten E (2016). "Immersive virtual reality improves movement patterns in patients after ACL reconstruction: implications for enhanced criteria-based return-to-sport rehabilitation." Knee Surg Sports Traumatol Arthrosc 24(7): 2280-2286.

Huskisson EC (1983). Visual analogue scales. In: Melzack R, ed. Pain measurement and assessment. New York: Raven,33-7. Jakobsen TL, Christensen M, Christensen SS, Olsen M, Bandholm T (2010). Reliability of knee joint range of motion and circumference measurements after total knee arthroplasty: does tester experience matter? Physiother Res Int, 15(3):126-34.

Lange T, Freiberg A, Dröge P, Lützner J, Schmitt J, Kopkow C (2015). The reliability of physical examination tests for the diagnosis of anterior cruciate ligament rupture-a systematic review. Manual therapy 20(3): 402-411.

Park EC, Kim SG, Lee CW (2015). The effects of virtual reality game exercise on balance and gait of the elderly. J Phys Ther Sci, 27(4):1157-9.

Priyanka P, Nilima B, Parag S, Ashok S (2017). Effects of Lumbar Core Stability Exercise Programme on Knee Pain, Range of Motion, and Function Post Anterior Cruciate Ligament Reconstruction. Journal of Orthopaedics, Trauma and Rehabilitation, 23;39-44.

Sadeghi H, Hakim MN, Hamid TA, Amri SB, Razeghi M, Farazdaghi M, Shakoor E (2017). The effect of exergaming on knee proprioception in older men: A randomized controlled trial. Arch Gerontol Geriatr, 69:144-150.

Takata Y, Nakase J, Toratani T, Numata H, Oshima T, Kitaoka K, Tsuchiya H (2017). Conscious performance and arthroscopic findings in athletes with anterior cruciate ligament injuries treated via conservative therapy during the competitive season. J Orthop Surg (Hong Kong). Jan;25(1): 2309499016684751.

Tichonova A, Rimdeikiene I, Petruseviciene D, Lendraitiene E (2016). The relationship between pain catastrophizing, kinesiophobia and subjective knee function during rehabilitation following anterior cruciate ligament reconstruction and meniscectomy: A pilot study. Medicina 52(4): 229-237. 